Article

\title{
Novel Edible Coating with Antioxidant and Antimicrobial Activities Based on Whey Protein Isolate Nanofibrils and Carvacrol and Its Application on Fresh-Cut Cheese
}

\author{
Qiannan Wang ${ }^{1}$, Hongliang Yu ${ }^{1}$, Bo Tian ${ }^{2}$, Bin Jiang ${ }^{1}{ }^{\circledR}$, Jing $\mathrm{Xu}^{1}{ }^{1}$, Dongmei $\mathrm{Li}^{1}$, \\ Zhibiao Feng ${ }^{1, *}$ and Chunhong Liu ${ }^{1, *(\mathbb{D})}$ \\ 1 Department of Applied Chemistry, College of Science, Northeast Agricultural University, \\ Harbin 150030, China; W18346111097@163.com (Q.W.); yuhongliang97@163.com (H.Y.); \\ jiangbin@neau.edu.cn (B.J.); xujing@neau.edu.cn (J.X.); lidongmei@neau.edu.cn (D.L.) \\ 2 College of Food Science, Northeast Agricultural University, Harbin 150030, China; tianbot@163.com \\ * Correspondence: fengzhibiao@neau.edu.cn (Z.F.); liuchunhong@neau.edu.cn (C.L.)
}

Received: 10 August 2019; Accepted: 12 September 2019; Published: 16 September 2019

\begin{abstract}
The composition and properties of edible coatings (ECs) will significantly influence their effects of food preservation. For the first time, whey protein isolates nanofibers (WPNFs), as a novel material with high hydrophobicity and antioxidant activity, combined with carvacrol (CA) as an antimicrobial agent and glycerol (Gly) as a plasticizer, was used to prepare edible coating (WPNFs-CA/Gly) for preserving fresh-cut Cheddar cheese. The prepared WPNFs and ECs emulsions have been investigated with transmission electron microscopy. Furthermore, the antioxidant activity of ECs emulsions, antimicrobial activity of edible films, and the physical properties of edible films, such as micromorphology, thickness, transparency, and moisture content, have also been evaluated. The weight losses and physical characteristics of both coated and uncoated fresh-cut Cheddar cheese samples have been assessed during storage. The DPPH free radical scavenging rate of WPNFs-CA/Gly emulsion was up to $67.89 \%$ and the reducing power was 0.821 , which was higher than that of WPI-CA/Gly emulsions. The antimicrobial activity of WPNFs-CA/Gly films was nearly 2.0-fold higher than that of WPNFs/Gly films for the presence of CA. The WPNFs-CA/Gly films had smooth and continuous surfaces, and the transparency reached $49.7 \%$ and the moisture content was $26.0 \%$, which was better than that of WPI-CA/Gly films. Furthermore, Cheddar cheese with WPNFs-CA/Gly coatings has shown lower weight losses (15.23\%) and better textural properties than those uncoated samples. This in-depth study has provided a valuable and noteworthy approach about the novel edible coating material.
\end{abstract}

Keywords: edible coating; whey protein isolate nanofibrils; antimicrobial activity; antioxidant activity; fresh-cut Cheddar cheese

\section{Introduction}

Various types of food proteins can be assembled into nanofibers (NFs) under mildly denaturing conditions, such as $\beta$-lactoglobulin ( $\beta$-lg) [1], whey protein isolates [2], ovalbumin [3], soy proteins [4], and pea protein [5]. Whey protein isolates (WPI), as a traditional industrial product [6], can be used as raw material for preparing whey protein isolates nanofibers (WPNFs) without any pretreatment. Meanwhile, WPNFs have improved techno-functional properties, including better foaming and emulsifying properties, self-supporting gelling ability, and increasing viscosity [7,8]. WPI has been more and more frequently used as raw material for preparing NFs. Widely utilized as efficient 
thickeners, gelators, foaming agents, foam stabilizers, and emulsifiers, WPNFs, the novel biocompatible nanomaterial, have become a promising candidate in the field of food research $[9,10]$.

WPNFs are well known as elongated unbranched fibrils, formed by perpendicularly placed and strictly stacked $\beta$-sheets of separate monomers [11]. The structures (such as fibril morphology, fibril length, and fibril flexibility) as well as functional properties of NFs can be influenced by many factors including raw materials, self-assembly processes, and post-fibrillation processes [10]. High aspect ratios of NFs may lead to an entangled network at a relatively low emulsion concentration, because of their ability of adsorption and unfolding on the interface, and the ability of viscoelastic interfacial film formation through molecular interactions [12].

Edible films and coatings (EFCs) based on natural ingredients such as proteins, polysaccharides, and lipid can be easily degraded [13]. They are attractive in the food industrial application for their potential to extend the food self-life through inhibiting lipid oxidation, reducing weight loss, and preventing antimicrobial components from adverse reactions (mainly oxidation and hydrolysis) $[14,15]$. Compared with traditional plastic films, the edible coatings (ECs) have received increasing attention in food packaging due to their bioactive functions, like lipid oxidation prevention and microbial growth inhibition, which may highly improve food quality during storage [16]. WPNFs can be made into transparent films with remarkable flexibility, antioxidant activity, and gas barrier property [17].

Antioxidant and antimicrobial activities of natural components, such as herbal extracts and essential oils, have been extensively studied [18]. They can be used as an alternative packaging material to synthetic preservatives by providing an additional antibacterial barrier against contaminations [19]. Among principal components of thyme and oregano essential oil, Carvacrol (CA), due to its excellent antimicrobial and antioxidant activities, has been regarded as a bioactive additive in edible coating and films to extend the shelf-life of pacific white shrimp [20], pumpkin [21], and tilapia fillets [13].

Cheese, mainly consisting of water, casein, and fat, is not only a popular dairy product worldwide, but also an ideal model of food coating processes because of its regular shape, uniform texture, and smooth surface [22]. In this study, the specific objective was to develop WPNFs, a novel edible coating material with CA and Gly, for maintaining the quality of fresh-cut Cheddar cheese. Micrographs, Fourier transform infrared spectroscopy, and antioxidant and antimicrobial activities of the edible coating emulsions and physical properties of edible films were observed. The effect of the ECs on weight loss and physical properties in fresh-cut Cheddar cheese slices stored at $4{ }^{\circ} \mathrm{C}$ were investigated.

\section{Materials and Methods}

\subsection{Materials}

WPI (protein content $>91.5 \%$ ) was acquired from Hilmar Industries (Hilmar, CA, USA). Trichloroacetic acid (TCA) was purchased from Sigma-Aldrich (St Louis, MO, USA). 1, 1-diphenyl-2picrylhydrazyl (DPPH) and Carvacrol (purity $>99.9 \%$ ) were obtained from Aladdin Reagent Co. (Shanghai, China). Potassium ferricyanide and iron chloride hexahydrate were purchased from (Tianjin, China). Pathogenic bacteria were obtained from BNCC Biological Technology Co., Ltd. (Nanjing, China). Cheddar cheeses were purchased from the local market (Harbin, China).

\subsection{Preparation and Characterization of Whey Protein Isolates Nanofibers (WPNFs)}

\subsubsection{Preparation of WPNFs}

WPNFs were prepared with the method described in our previous study, with some modifications [17]. $3 \mathrm{M}$ hydrochloric acid was used for $\mathrm{pH}$ adjustment of $5 \%$ WPI solution (w/w) until the $\mathrm{pH}$ value was stable at 2.0. The acidic solution was stirred at room temperature for $30 \mathrm{~min}$ to fulfill the protein hydration, and then centrifuged $\left(4^{\circ} \mathrm{C}\right)$ at $9000 \times g$ (Z236HK Hermle, Wehingen, Germany) for $15 \mathrm{~min}$. The supernatant was vacuum filtered through a $0.45-\mu \mathrm{m}$ cellulose acetate membrane filter (Aladdin, Shanghai, China) to remove undissolved protein. WPNFs were prepared by $10 \mathrm{~h}$ filtrate 
incubation under at $80{ }^{\circ} \mathrm{C}$ with $220 \mathrm{rpm}$ constant magnetic stirring. After the fibrillation process, samples were cooled down rapidly to terminate the reaction with cold tap water at approximate rate of $10{ }^{\circ} \mathrm{C} / \mathrm{min}$. The WPNFs emulsion were stored under $4{ }^{\circ} \mathrm{C}$ until analysis. $5 \%$ WPI solution $(\mathrm{w} / \mathrm{w})$ was used as control in the next-stage experiments.

\subsubsection{Transmission Electron Microscopy (TEM)}

WPNFs solution was ultrafiltered for the TEM background reduction based on the previous method [23]. Briefly, WPNFs solution was diluted approximately 10-fold with $\mathrm{HCl}$ solution ( $\mathrm{pH} 2.0$ ), and then ultrafiltered with nominal cutoff of $100 \mathrm{kDa}$ at $3000 \times g$ for $15 \mathrm{~min}$. The filtration procedure was repeated three times, and the total retentate was collected and resolved with $1 \mathrm{~mL} \mathrm{HCl}$ solution ( $\mathrm{pH}$ 2.0) in a new 1.5-mL plastic tube. The WPNFs solution was slowly dripped on a special copper mesh (The diameter of the copper mesh is $3 \mathrm{~mm}$ and the thickness is $10-30 \mu \mathrm{m}$.). After standing for $15 \mathrm{~min}$, redundant liquid was gently absorbed with a piece of filter paper. $2 \%$ uranyl acetate was then added drop by drop on the dried mesh and the copper stood ventilated for $8 \mathrm{~min}$. Before TEM measurements, the mesh was absorbed again to remove unneeded solution. Electron micrographs were captured by an H-7650 transmission electron microscope (Hitachi, Tokyo, Japan).

\subsection{Preparation and Functional Properties of Edible Coatings (ECs) Emulsions}

\subsubsection{Preparation of Edible Coating Emulsions}

The WPNFs-CA/Gly edible coating emulsion consisted of $94.5 \mathrm{~g}$ WPNFs solution as emulsifier, $5 \mathrm{~g}$ Gly $(5 \%, \mathrm{w} / \mathrm{w})$ as a plasticizer, and $0.5 \mathrm{~g}$ CA $(0.5 \%, \mathrm{w} / \mathrm{w})$ as a bacteriostat. The first step was to prepare WPNFs-CA emulsion. CA was added to WPNFs solution, and the WPNFs-CA emulsion were treated by high shear homogenization at $5000 \mathrm{rpm}$ for $1 \mathrm{~min}$ (ESB-500, ELE Company, Shanghai, China). The emulsion was then homogenized under $40 \mathrm{MPa}$ with 4 passes by a Panda $2 \mathrm{~K}$ high-pressure homogenizer (NiroSoavi Deutschland, Lübeck, Germany). Furthermore, Gly was added to the WPNFs-CA emulsion as plasticizer. After $90^{\circ} \mathrm{C}$ stir for $30 \mathrm{~min}$, WPNFs-CA/Gly emulsion was vacuumed to eliminate dissolved air, and was cooled to room temperature. In addition, WPI/Gly, WPNFs/Gly and WPI-CA/Gly emulsions were prepared by the similar procedure, with the replacement of $\mathrm{CA}$ to distilled water.

\subsubsection{Morphology of the Edible Coating Emulsions}

A drop of 10-fold-diluted sample was placed on a coated copper grid, $0.5 \%$ phosphotungstic acid was applied as a negative staining agent, and the grid was air-dried and held for $8 \mathrm{~min}$. Electron micrographs were observed by TEM (H-7650 transmission electron microscope, Hitachi, Tokyo, Japan).

\subsubsection{Fourier Transform Infrared Spectroscopy (FT-IR)}

The spectra of the edible coating emulsions were recorded with an ALPHA-T Fourier transform infrared spectrometer (Bruker Instrument, Ettlingen, Germany). The freeze-dried samples were ground with potassium bromide, and compressed into disks. Transmittance spectra were collected between 400 and $4000 \mathrm{~cm}^{-1}$ with a resolution ratio of $4 \mathrm{~cm}^{-1}$. Each sample was scanned 64 scans in a transmittance mode. Raw data were imported in OPUS 6.0 software for second-derivative treatment and Fourier deconvolution ( $18 \mathrm{~cm}^{-1}$ full width at half maximum; 2.8 enhancement factor). The curve-fitted spectra were saved for further analysis [24].

\subsubsection{Antioxidant Activity of the Edible Coating Emulsions}

DPPH Free Radical Scavenging Assay

DPPH radical scavenging activity of the edible coating emulsion was determined as reported by Miliauskas et al. [25] with some modifications. The Edible coating emulsion (1.0 mL) was added to 
$4.0 \mathrm{~mL}$ DPPH solution (0.1 mM DPPH dissolved in 95\% ethanol). The mixture was then vortexed and stood in darkness for $30 \mathrm{~min}$ at room temperature. After that, the absorbance of the mixture at $517 \mathrm{~nm}$ was determined with a UV-2500 spectrophotometer (Shimadzu, Tokyo, Japan). 95\% ethanol was used as blank. The percentage inhibition was calculated by the following formula:

$$
\text { Antioxidant activity }(\%)=\left(1-\frac{A_{\mathrm{i}}-A_{\mathrm{j}}}{A_{\mathrm{c}}}\right) \times 100
$$

where $A_{\mathrm{i}}$ represented the absorbance of EC samples, $A_{\mathrm{j}}$ represented the absorbance of the control sample, and $A_{\mathrm{c}}$ represented the absorbance of the blank.

\section{Reducing Power}

Reducing power of the edible coating emulsion was tested using the method described by Schmitt et al. [26] with several modifications. The mixture of $0.1 \mathrm{~mL}$ EC sample, $0.5 \mathrm{~mL}$ potassium ferricyanide $(1 \%, \mathrm{w} / \mathrm{v})$ and $0.4 \mathrm{~mL}$ phosphate buffer $(0.2 \mathrm{M}, \mathrm{pH} 6.6)$ was incubated at $50{ }^{\circ} \mathrm{C}$ for $20 \mathrm{~min}$. After adding $0.5 \mathrm{~mL}$ trichloroacetic acid $(10 \%, \mathrm{w} / \mathrm{v})$, the mixture was vortexed and centrifuged at $3000 \times \mathrm{g}$ for $10 \mathrm{~min}$. The supernatant was transferred and mixed with deionized water and $0.1 \%$ ferric chloride $(5: 5: 1, \mathrm{v} / \mathrm{v} / \mathrm{v})$. After being kept at room temperature for $10 \mathrm{~min}$, the absorbance at $700 \mathrm{~nm}$ was measured spectrophotometrically.

\subsection{Preparation and Functional Properties of Edible Films (EFs)}

\subsubsection{Preparation of Edible Films}

In order to ensure the characterization integrity of EC materials, different edible coating emulsions were formed into films with Teflon-coated plates (i.d. $15 \mathrm{~cm}$ ). $20 \mathrm{~mL}$ of the degassed emulsions were pipetted into the plates and placed under $60^{\circ} \mathrm{C}$ for $18 \mathrm{~h}$ in the temperature-controlled chamber (Blue-Pard Pharma, Shanghai, China).

\subsubsection{Antimicrobial Activity of the EFs}

The antimicrobial activities of emulsions were determined by agar disk diffusion method against typical gram-positive bacteria: Listeria monocytogenes (CMCC 54004) and Staphylococcus aureus (CMCC 26112), as well as gram-negative bacteria: Salmonella enteritidis (CMCC 50,071 and Escherichia coli (CMCC 44113) [27]. $100 \mu \mathrm{L}$ bacteria suspension $\left(10^{7} \mathrm{CFU} / \mathrm{mL}\right)$ was smeared evenly on the Mueller-Hinton agar plate (Aladdin Reagent Co. Shanghai, China). An EFs disc (10-mm diameter) was positioned on the center of the inoculated plate. The agar plates were sealed and stood for $30 \mathrm{~min}$, followed by $37^{\circ} \mathrm{C}$ incubation for $24 \mathrm{~h}$. The diameters ( $\mathrm{mm}$ ) of inhibition zones were determined with a caliper (Deli Co., Ninghai, China). Three duplications were performed for each sample.

\subsubsection{Physical Properties of Edible Films}

Scanning Electron Microscopy (SEM)

The surface and cross-section of the edible films were determined with S-3400N Scanning electron microscopy (Hitachi, Tokyo, Japan). The cryo-fractured film samples were mounted horizontally and perpendicularly on the bronze stubs, which a thin layer of gold was then sputtered on the surface for electric conduction. A silicon probe (Hitachi, Tokyo, Japan) of 125-mm cantilever length was chosen for measurement. The resonant frequency was set at approximately $500 \mathrm{kHz}$. The scan rates were set $0.5 \sim 1.0 \mathrm{~Hz}$.

Film Thickness 
The thickness of the edible films was estimated after conditioned at $25^{\circ} \mathrm{C}$ for $24 \mathrm{~h}$ with a digital external micrometer (Mitutoyo Co., Kawasaki, Japan). Averaged thickness obtained by measuring the film at 10 different points.

Transparency Measurement

The transparency of film samples was tested using a Shimadzu UV-2500 spectrophotometer (Tokyo, Japan). Rectangular film pieces $(1 \mathrm{~cm} \times 4 \mathrm{~cm})$ were cut and attached to one side of a colorimetric cup. An empty colorimetric cup was measured for test control. Three duplications of each film were measured to guarantee the accuracy. The transparency of the film was determined at $600 \mathrm{~nm}$ and the relative transparency was calculated as follows:

$$
\text { Transparency }(\%)=\left(\frac{T_{600}}{d}\right) \times 100
$$

where, $T_{600}$ stood for the film transparency at $600 \mathrm{~nm} ; d$ stood for the averaged thickness (mm).

Moisture Content (MC) Measurement

The film pieces $(1 \mathrm{~cm} \times 3 \mathrm{~cm})$ were weighed immediately after cutting. Then they were dried and treated under $105{ }^{\circ} \mathrm{C}$ with an air-circulating oven until they reached a constant weight, and final weights of films were recorded. The MC value was expressed as a fraction of sample weight lost during drying [28].

\subsection{Coated Cheese Quality Assessment}

\subsubsection{Preparation of Cheese Samples and Treatments}

Sealed cheeses were stored at $4{ }^{\circ} \mathrm{C}$ until coating treatments. After unsealing the package, cheese was cut into $3 \mathrm{~cm} \times 3 \mathrm{~cm} \times 0.5 \mathrm{~cm}$ pieces immediately. Control and coated samples were assigned randomly. Cheese slices were soaked in the edible coating emulsion for $1 \mathrm{~min}$ and drained for $30 \mathrm{~min}$ at room temperature. Cheeses coated with WPI/Gly, WPI-CA/Gly, WPNFs/Gly, and WPNFs-CA/Gly coating and uncoated cheese (control samples) were stored properly under $4{ }^{\circ} \mathrm{C}$ for 10 days. At least three duplications were performed for each sample.

\subsubsection{Evaluation of Physicochemical Properties of Coated Cheese}

\section{Weight Loss Measurement}

Weight loss in cheese pieces is mainly caused by water loss. In this study, weight loss was represented by a percentage calculating the difference between the initial cheese weight $\left(W_{i}\right)$ and the cheese weight measured at different storage time points $\left(W_{\mathrm{f}}\right)$. The formula was as follows:

$$
\text { Weight loss }(\%)=\left(\frac{W_{i}-W_{f}}{W_{i}}\right) \times 100
$$

\section{Texture Property of Coated Cheese}

Texture properties of cheese slices were measured with a TA-plus texture analyzer (Stable Micro Systems, Goldaming, UK). The hardness, cohesiveness, springiness, and chewiness of the cheese slices were tested on random sample locations (main body and edges) [22]. Eight replicates of each tray were performed. The test parameters were as follows: a $25 \mathrm{~mm}$ diameter perplex cone probe, pre-speed and post-speed were set at $5.0 \mathrm{~mm} / \mathrm{s}$, test speed was set at $0.4 \mathrm{~mm} / \mathrm{s}$, distance was set at $50 \%$, and rupture test was set at $1.0 \%$.

Color of the Cheese Surface 
Color value of the cheese surface was monitored with a $\mathrm{Cr} 410$ Minolta colorimeter (Konica Minolta, Tokyo, Japan). White and black ceramic plates were used for colorimeter pre-standardization. Six random locations were measured for each sample, and the data were reported as $L^{*}, a^{*}$, and $b^{*}$ values, where $L^{*}$ values represented black $(0)$ to white $(100), a^{*}$ values indicated red $(+)$ to green $(-)$, and $b^{*}$ values stood for yellow $(+)$ to blue $(-)[28,29]$.

\subsection{Statistical Analysis}

Statistical analyses were performed with SPSS 20.0 software (Chicago, IL, USA). All figures and tables are shown by mean values with the standard deviation (means \pm SD). Significant differences $(p<0.05)$ were calculated by Duncan's multiple range algorithm.

\section{Results and Discussion}

\subsection{Morphology of Whey Protein Isolates Nanofibers (WPNFs)}

Negatively stained samples were used to characterize the fibril morphology with the help of the transmission electron microscopy (TEM) analysis. Figure $1 \mathrm{a}$ and b showed the TEM images of WPI and WPNFs. Consistent with previous research, elongated unbranched WPNFs were formed with several-micrometer length after 10-h incubation at pH 2.0 (Figure 1b) [1,30]. The extent of each functionality strongly depends on the length distribution of the fibrils, such as gelling agent, foam, and emulsion stabilizer [10].

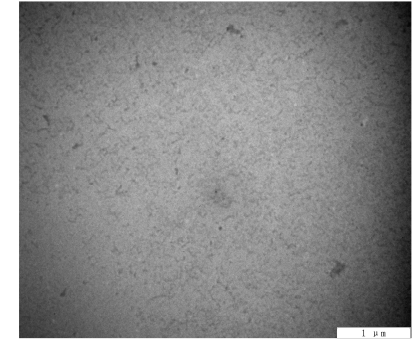

(a)

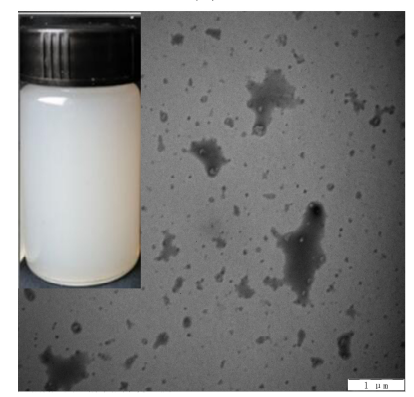

(c)

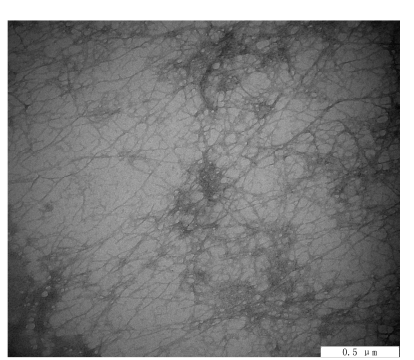

(b)

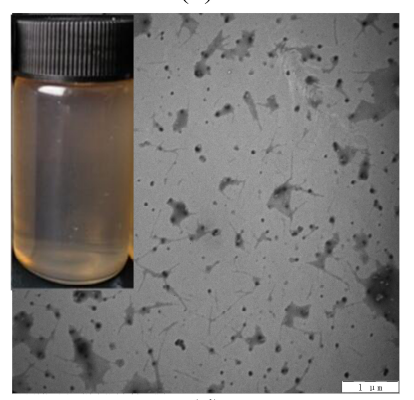

(d)

Figure 1. Transmission electron microscopy (TEM) micrographs (negatively stained method) of why protein isolates nanofibers (WPNFs) and edible coating emulsions. (a) native whey protein isolate (WPI); (b) WPNFs, prepared by heating 5\% WPI at $80{ }^{\circ} \mathrm{C}$ and $\mathrm{pH} 2.0$ for $10 \mathrm{~h}$; (c) whey protein isolate-carvacrol/glycerol (WPI-CA/Gly) emulsion; (d) WPNFs-CA/Gly emulsion.

\subsection{Functional Properties of Edible Coating Emulsions}

\subsubsection{Appearance and Morphology of Edible Coating Emulsions}

The appearance and microstructure of edible coating emulsions were shown in Figure 1c,d. WPI-CA/Gly emulsion presented non-clear and milky white, while WPNFs-CA/Gly emulsion was brownish with better transparency. Transmission electron micrographs of emulsions demonstrated WPNFs-CA/Gly emulsion had spherical droplets with smaller diameter and better distribution in 
the system than WPI-CA/Gly emulsion. WPNFs adsorbed at the surface of droplets as a barrier between droplets could prevent droplets aggregation [31]. Meanwhile, owing to the weak non-covalent interactions, WPNFs were easily shortened under high-shear and high-pressure homogenization. The short fibers had a better coverage of small oil droplets which might lead to improved emulsion stability [32].

\subsubsection{FT-IR of Edible Coating Emulsions}

Proteins contain certain structural fractions, for example $\alpha$-helix and $\beta$-sheet. FT-IR spectroscopy is one of the major applications to estimate protein secondary structures $[33,34]$. In this research, FT-IR spectroscopy was utilized to investigate the structural changes of the emulsions (Figure 2). Many absorption peaks of CA were due to its characteristic groups including phenolic hydroxyl (a broad band around $3426 \mathrm{~cm}^{-1}, \mathrm{O}-\mathrm{H}$ stretching) and aromatic rings (1255 $\mathrm{cm}^{-1}, \mathrm{C}-\mathrm{O}$ deformation;). However, the phenolic hydroxyl were weakened in WPI-CA/Gly and WPNFs-CA/Gly, at the same time, typical amide bond absorption peaks were enhanced $\left(3260 \mathrm{~cm}^{-1}, \mathrm{O}-\mathrm{H}\right.$ and $\mathrm{N}-\mathrm{H}$ stretching; 1533 and $1654 \mathrm{~cm}^{-1} \mathrm{~N}-\mathrm{H}$ bending), which might be caused by the interaction between the hydroxyl groups of $\mathrm{CA}$ and amino groups of proteins.

Amid I region (between 1700 to $1600 \mathrm{~cm}^{-1}$ ) of FT-IR spectra, represents stretching vibrations of $\mathrm{C}=\mathrm{O}$ groups, and is directly associated with protein secondary structures [34]. Infrared spectra were subjected to the second-derivative analysis (IR-SD) to quantitatively and qualitatively analyze the secondary structures of protein components. As presented in Table 1, in the absence of CA, WPNFs/Gly had higher $\beta$-sheet content than WPI/Gly mainly because WPNFs were unbranched fibrils rich in $\beta$-structures [1]. The content of $\beta$-sheet and random coils decreased slightly for the presence of $C A$, suggesting that there were hydrogen bonding and hydrophobic interactions between CA and WPI or WPNFs $[35,36]$.

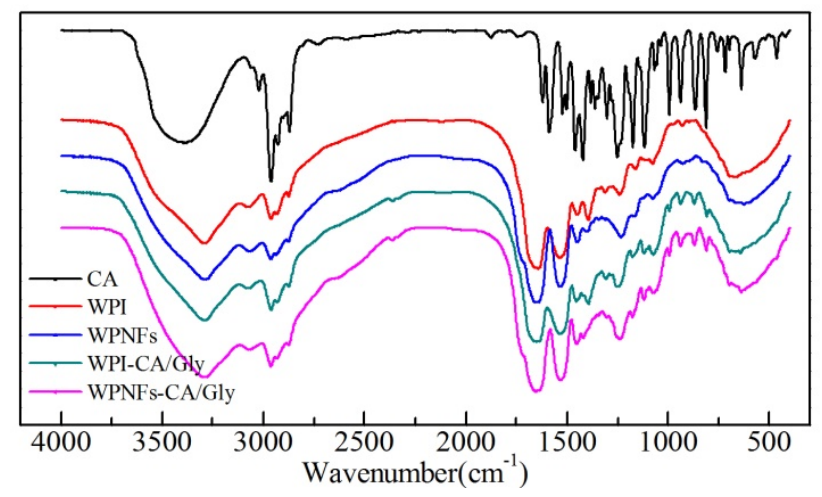

Figure 2. FT-IR spectra of edible coating emulsions.

Table 1. Curve-fitting results of the secondary structures (WPI = whey protein isolate, Gly = glycerol, $\mathrm{WPNFs}=$ whey protein isolates nanofibers, $\mathrm{CA}=$ carvacrol $)$.

\begin{tabular}{ccccc}
\hline Emulsions & $\boldsymbol{\beta}$-Sheet (\%) & Random Coils (\%) & $\boldsymbol{\alpha}$-Helix (\%) & $\boldsymbol{\beta}$-Turn (\%) \\
\hline WPI/Gly & 28.62 & 21.76 & 18.51 & 31.11 \\
WPNFs/Gly & 46.52 & 17.17 & 13.97 & 22.34 \\
WPI-CA/Gly & 26.36 & 17.59 & 21.53 & 34.52 \\
WPNFs-CA/Gly & 42.04 & 16.79 & 15.69 & 23.48 \\
\hline
\end{tabular}

\subsubsection{Antioxidant Activity of Edible Coating Emulsions}

The antioxidant activity of the edible coating emulsions was determined by reducing power and DPPH scavenging assays (Figure 3). WPNFs/Gly emulsion had higher antioxidant activity in both reducing power and DPPH radical scavenging activity than WPI/Gly emulsion. This was directly 
related to the higher radical scavenging capability of WPNFs, and it was due to the generation of bioactive peptides during the fibrillation process $[37,38]$. CA, as a natural antioxidant and bacteriostat, was also could improve the antioxidant capacity of coating emulsions. The results proved that the effect of DPPH scavenging assays and reducing power was distinct and enormous. Additionally, the reducing power of WPI-CA/Gly and WPNFs-CA/Gly emulsions were larger than the sum of its components, this illustrated the synergistic effect of CA with WPI or WPNFs. Compared with WPI-CA/Gly, DPPH free radical scavenging rate of WPNFs-CA/Gly emulsion was up to $67.89 \%$ and the reducing power was 0.821 , which was higher than that of WPI-CA/Gly emulsions. Therefore, the WPNFs-CA/Gly emulsion could be applied as an edible coating to prevent oxidation in food matrices.
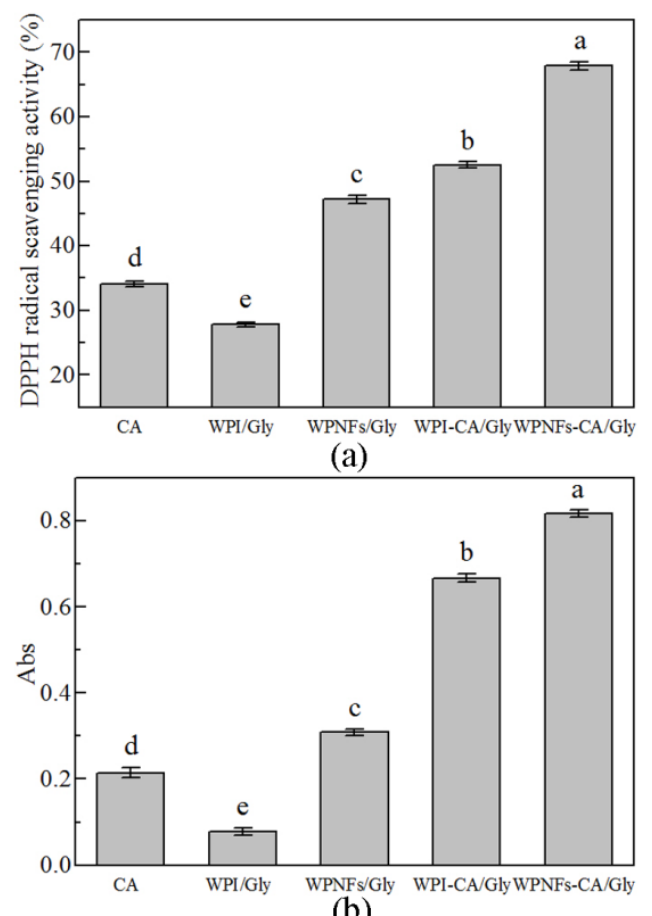

Figure 3. 1,1-diphenyl-2-picrylhydrazyl (DPPH) radical scavenging activity (a) and reducing power (b) of samples including carvacrol (CA) dispersed in distilled water by high pressure homogenization (CA), whey protein isolate/glycerol (WPI/Gly), whey protein isolates nanofibers (WPNFs)/Gly, WPI-CA/Gly and WPNFs-CA/Gly emulsions. Means followed by different letters are significantly different $(\mathrm{p}<0.05)$. Error bars indicate the standard deviation of the mean.

\subsection{Functional Properties of Edible Films (EFs)}

\subsubsection{Antibacterial Activity of EFs}

Due to the uncontrolled and extensive contamination of fungi and bacteria, the shelf life of cheese products has been greatly limited. Fungal and bacterial growth can reduce their qualities by discoloration, textural changes, and off-flavor development, especially after being cut [39]. The effectiveness of edible films in inhibiting two gram-positive bacteria (L. monocytogenes and S. aureus) and two gram-negative bacteria (S. enteritidis and E. coli) was shown in Figure 4. The inhibition zones of WPI/Gly film against the four microorganisms were zero, meaning that there have been no inhibitory effects on them for the absence of antimicrobial compound in the film. Meanwhile, it was noteworthy that the WPNFs/Gly film presented a minute inhibition zone, probably because of the antioxidant ability of WPNFs [17]. The antimicrobial activity of WPNFs-CA/Gly films was nearly 2.0-fold higher than that of WPNFs/Gly films for the presence of CA. This is because the presence of CA significantly strengthened the antimicrobial activity of the edible film. Better antimicrobial effects 
of the WPNFs-CA/Gly film have been demonstrated than WPI-CA/Gly film, suggesting that the size reduction of the essential oil droplet in emulsion would induce a faster penetrate rate of antimicrobial compounds in the bacterial cell, and would then lead to more remarkable antimicrobial behavior [40].

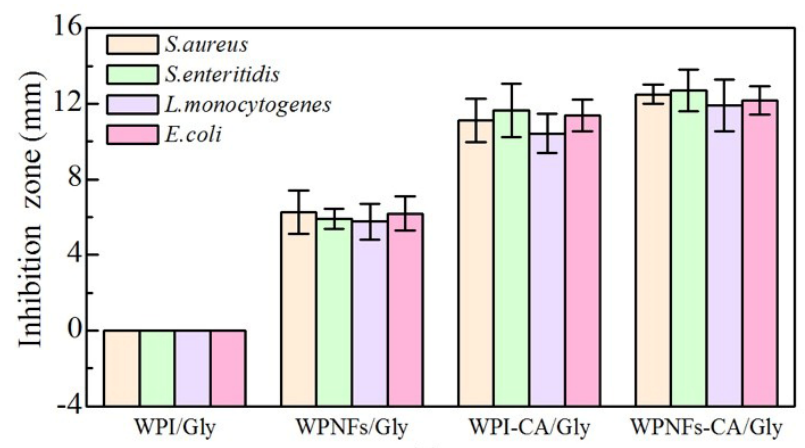

(a)
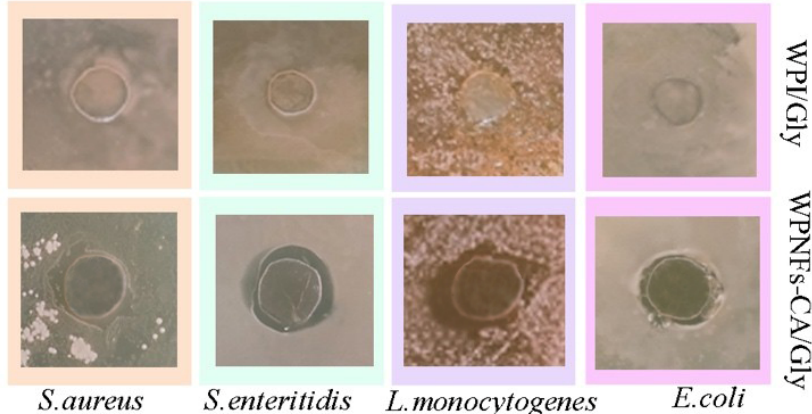

(b)

Figure 4. Antimicrobial activity of edible films against Listeria monocytogenes (CMCC 54004), Staphylococcus aureus (CMCC 26112), Salmonella enteritidis (CMCC 50071), and Escherichia coli (CMCC 44113). (a) The inhibition zones of edible films; (b) Representative picture of inhibitory zones of whey protein isolate/glycerol (WPI/Gly) and whey protein isolates nanofibers-carvacrol (WPNFs-CA)/Gly films. Error bars indicate the standard deviation of the mean.

\subsubsection{Microstructure of EFs}

For better property characterization of the edible coating, emulsions mentioned above had been prepared into films. SEM were used to capture the microstructures of surface and cross-section of the films and results were revealed in Figure 5. The surface and cross-section of WPI/Gly film were rough, densely distributed with disperse irregular particles, and had some pores. The WPNFs-based (WPNFs/Gly and WPNFs-CA/Gly) films had smooth and continuous surfaces. Meanwhile, a homogeneous and compact interior structure without pores was observed in both WPNFs-based films. This indicated that the WPNFs-based emulsions could form one-component hydrocolloid films with the well-organized network structures [17], and CA could stay homogeneously distributed in the dry protein matrix. 

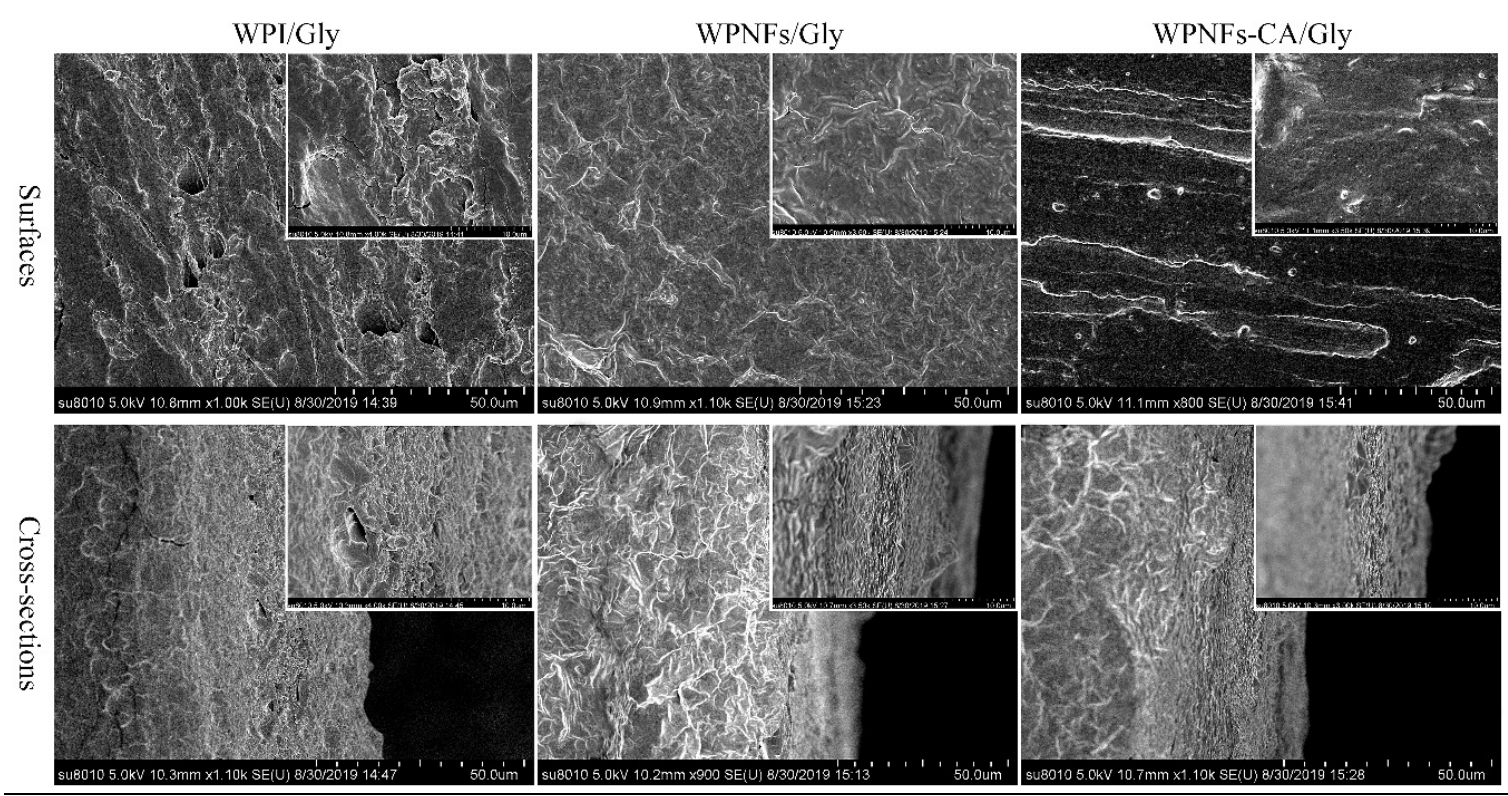

Figure 5. Scanning electron microscopy images of the surfaces and cross-sections of edible films (The inserted images were a higher magnification images of the corresponding films.).

\subsubsection{Film Thickness}

The thickness and transparency of the edible film were presented in Table 2. The film thickness of WPI/Gly, WPNFs/Gly, WPI-CA/Gly, and WPNFs-CA/Gly films were $0.184,0.182,0.232$, and $0.226 \mathrm{~mm}$, respectively. No significant differences were shown in thickness between the WPI/Gly and WPNFs/Gly films, indicating that the formation of WPNFs did not affect the thicknesses. For the presence of CA, the film thickness had been significantly increased $(p<0.05)$, indicating that the combination of proteins and CA with hydrophobic interactions could lead to various rearrangements among protein matrices, and could consequently show influence on film thickness [41].

Table 2. Mean film thickness, transparency, and moisture content of films.

\begin{tabular}{cccc}
\hline Films & Thickness $(\mathbf{m m})$ & Transparency (\%) & Moisture Content (\%) \\
\hline WPI/Gly & $0.184 \pm 0.066 \mathrm{~b}$ & $45.7 \pm 1.3 \mathrm{~b}$ & $44.2 \pm 1.6 \mathrm{a}$ \\
WPNFs/Gly & $0.182 \pm 0.034 \mathrm{~b}$ & $49.2 \pm 1.4 \mathrm{a}$ & $32.8 \pm 0.9 \mathrm{~b}$ \\
WPI-CA/Gly & $0.232 \pm 0.045 \mathrm{a}$ & $41.5 \pm 0.1 \mathrm{c}$ & $34.6 \pm 1.1 \mathrm{~b}$ \\
WPNFs-CA/Gly & $0.226 \pm 0.038 \mathrm{a}$ & $49.7 \pm 1.1 \mathrm{a}$ & $26.0 \pm 1.2 \mathrm{c}$ \\
\hline
\end{tabular}

Different letters mean significant difference at $p<0.05$ in same column.

\subsubsection{Transparency of EFs}

Transparency of the food packaging films is an important property in marketing perspective [42]. The transparency of the edible film was shown in Table 2. The WPNFs-based films had better transparency than WPI-based films $(p<0.05)$. This was also due to the smooth and continuous surface of WPNFs-based films, while the rough surface of WPI substrates increased the opacity for light scattering effect.

\subsubsection{Moisture Content of EFs}

As shown in Table 2, the mean moisture content value of WPNFs/Gly films was significantly lower than that of WPI/Gly films $(p<0.05)$, indicating WPNFs/Gly films could not absorb as much water as WPI/Gly films. Similar research results have been reported that the well-organized $\beta$-sheet structures induced in the formation of WPNFs would lead to a higher hydrophobicity and would 
restrict water uptake [43]. The presence of CA has significantly reduced the moisture content values of films. The results were consistent with previous research that adding essential oils (e.g., apricot kernel essential oil) to chitosan films has decreased moisture content values [42].

\subsection{Functional Properties of the Edible Coatings (ECs) on the Preservation of Cheese Pieces}

\subsubsection{Weight Loss of Coated Cheese Slice}

The weight loss of cheese is mainly the result of moisture loss. During storage, cheese shrinkage can cause adverse effects on both product appearance and nutritional quality. In general, coated cheese products have shown better weight loss performance when compared with uncoated counterparts [44]. Figure 6 showed the effects of coating treatment on weight loss of cheese slices during $4{ }^{\circ} \mathrm{C}$ storage for 10 days. Since the moisture has continuously evaporated from cheese to ambient environment, the weight loss in all cases have been linearly increased with storage time [22]. Cheese samples with WPNFs-based coatings have been efficiently preserved with a mean weight loss of $15.23 \%$ and $15.41 \%$ over 10 days storage, compared with approximately $21.85 \%$ in the control sample. This was mainly because WPNFs-based coating could form one-component hydrocolloid films with the well-organized network structure. The water vapor barrier of WPNFs-CA/Gly coating had the best effect in minimizing moisture evaporation.

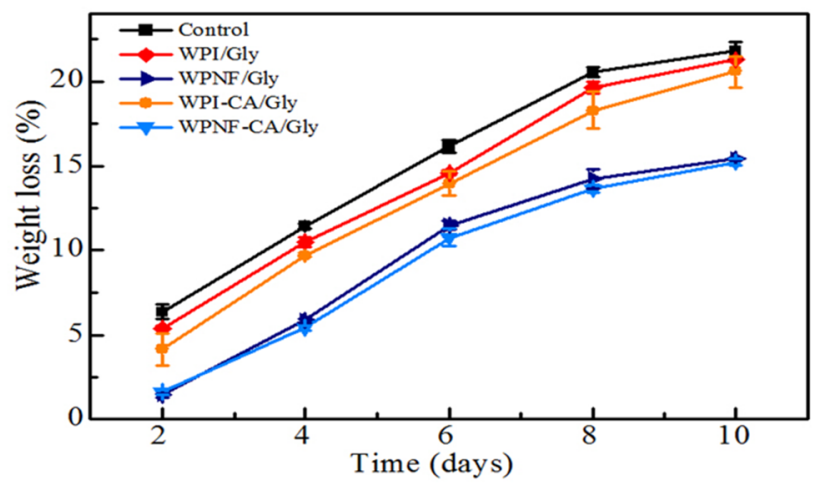

Figure 6. Weight loss of coated cheese slice during the storage periods for samples stored 10 days at $4{ }^{\circ} \mathrm{C}$. Error bars indicate the standard deviation of the mean.

\subsubsection{Texture Property of Coated Cheese}

Texture profile analyses were carried out based on the compression tests, and all Cheddar cheese samples showed considerable changes in texture properties for 10 days storage (Table 3$)$. The hardness of all coated samples has been significantly increased $(p<0.05)$, which was highly correlated with the weight loss results during storage (Figure 6). The tendency was same with previous research report that the hardness of fresh cheese increased in correlation with the moisture level over time [22]. At the first day, the hardness of uncoated cheese was $23.08 \mathrm{~N}$, but that of the coated counterparts exhibited significant declines $(p<0.05)$. It seemed that because of the water presented in the coating, higher hydration might have contributed to the decreased hardness. Due to the excessive water loss, the cohesiveness, chewiness, and springiness of the cheese samples with WPI-based coatings were beyond the range of determination and lost the texture property. However, the WPNFs-based coating had significant effects on the cohesiveness, chewiness, and springiness of Cheddar cheese $(p<0.05)$. Cohesiveness and chewiness of WPNFs-based emulsions coated cheese samples showed more variations with significant changes $(p<0.05)$ throughout storage, while springiness of them remained stable $(p>0.05)$. The WPNFs-based coatings produced the softest cheese texture, which might be attributed to its favorable water retention capability. 
Table 3. Texture profile analysis of coated cheeses during storage at $4{ }^{\circ} \mathrm{C}$.

\begin{tabular}{|c|c|c|c|c|c|c|c|c|}
\hline \multirow[t]{2}{*}{ Films } & \multicolumn{2}{|c|}{ Hardness (N) } & \multicolumn{2}{|c|}{ Cohesiveness Area (B/A) } & \multicolumn{2}{|c|}{ Chewiness (N/m) } & \multicolumn{2}{|c|}{ Springiness (Mm) } \\
\hline & $0 \mathrm{~d}$ & $10 \mathrm{~d}$ & $0 \mathrm{~d}$ & $10 \mathrm{~d}$ & $0 \mathrm{~d}$ & $10 \mathrm{~d}$ & $0 \mathrm{~d}$ & $10 \mathrm{~d}$ \\
\hline Control & $\begin{array}{c}23.08 \pm \\
0.47 \mathrm{e}\end{array}$ & $\begin{array}{c}59.49 \pm \\
0.12 \mathrm{a}\end{array}$ & $\begin{array}{c}0.65 \pm \\
0.04 \mathrm{a}\end{array}$ & - & $\begin{array}{c}15.48 \pm \\
0.88 \mathrm{~b}\end{array}$ & - & $\begin{array}{c}0.91 \pm \\
0.03 a\end{array}$ & - \\
\hline WPI/Gly & $\begin{array}{c}19.70 \pm \\
0.28 \mathrm{f}\end{array}$ & $\begin{array}{c}58.57 \pm \\
0.24 \mathrm{~b}\end{array}$ & $\begin{array}{c}0.54 \pm \\
0.06 b\end{array}$ & - & $\begin{array}{c}14.13 \pm \\
0.24 b\end{array}$ & - & $\begin{array}{c}0.81 \pm \\
0.02 \mathrm{a}\end{array}$ & - \\
\hline WPI-CA/Gly & $\begin{array}{c}19.42 \pm \\
0.14 f\end{array}$ & $\begin{array}{c}58.18 \pm \\
0.34 \mathrm{~b}\end{array}$ & $\begin{array}{c}0.52 \pm \\
0.01 \mathrm{~b}\end{array}$ & - & $\begin{array}{c}14.87 \pm \\
0.27 b\end{array}$ & - & $\begin{array}{c}0.84 \pm \\
0.03 a\end{array}$ & - \\
\hline WPNFs/Gly & $\begin{array}{c}19.10 \pm \\
0.63 \mathrm{f}\end{array}$ & $\begin{array}{c}52.37 \pm \\
0.44 \mathrm{c}\end{array}$ & $\begin{array}{c}0.55 \pm \\
0.04 b\end{array}$ & $\begin{array}{c}0.42 \pm \\
0.04 \mathrm{c}\end{array}$ & $\begin{array}{c}15.44 \pm \\
0.37 \mathrm{~b}\end{array}$ & $\begin{array}{c}27.94 \pm \\
0.24 \mathrm{a}\end{array}$ & $\begin{array}{c}0.84 \pm \\
0.11 \mathrm{a}\end{array}$ & $\begin{array}{c}0.89 \pm \\
0.01 \mathrm{a}\end{array}$ \\
\hline WPNFs-CA/Gly & $\begin{array}{c}18.40 \pm \\
0.58 \mathrm{f}\end{array}$ & $\begin{array}{c}51.11 \pm \\
0.32 \mathrm{~d}\end{array}$ & $\begin{array}{c}0.53 \pm \\
0.03 b\end{array}$ & $\begin{array}{c}0.43 \pm \\
0.04 \mathrm{c}\end{array}$ & $\begin{array}{c}15.94 \pm \\
0.53 b\end{array}$ & $\begin{array}{c}28.22 \pm \\
0.36 \mathrm{a}\end{array}$ & $\begin{array}{c}0.91 \pm \\
0.01 \mathrm{a}\end{array}$ & $\begin{array}{c}0.89 \pm \\
0.10 \mathrm{a}\end{array}$ \\
\hline
\end{tabular}

The data (mean \pm standard deviation) derived from three replicates. a-f different superscript letters represent significant differences at $p<0.05$ in the means of the same parameter. - means the measurement value out of the instrument measurement range $(\mathrm{WPI}=$ whey protein isolate, $\mathrm{Gly}=$ glycerol, $\mathrm{CA}=$ carvacrol, $\mathrm{WPNFs}=$ whey protein isolate nanofibers).

\subsubsection{Color Changes of the Cheese Pieces}

Coatings had shown obvious influences on color changes, and the test results of their effects were shown in Figure 7. The luminosity $\left(L^{*}\right)$ of the cheese samples showed that all different coatings have made the slices more luminous. The luminosity of cheese slices significantly decreased during storage $(p<0.05)$, which might be due to the microbial growth on cheese surface [22]. At the end of the storage, the luminosity decrease rate of uncoated cheese samples was $16.9 \%$, in comparison to less than $6.7 \%$ of WPNFs-CA/Gly counterpart.

The $a^{*}$ value showed the greenish or reddish color of cheese slices with the range from the green region $(-a)$ to the red region $(+a)$. On the one hand, the greenness showed no significant differences between coated cheese samples and uncoated samples $(p>0.05)$. The $a^{*}$ value, on the other hand, developed a rising trend during storage. The reddish color change might be attributed to the microbial growth on cheese surfaces during the test period. There was a thin pink layer observed on the cheese surface due to microbial spoilage, which was reflected in the color measurements [44]. Coatings with CA showed minimum changes in $a^{*}$ values, indicating that they had a preferable ability to inhibit microorganisms and maintain the cheese quality.

The $b^{*}$ value was used to describe changes in the blue-yellow region for different coating cheese slices. Initially, the milky white color of WPI-based coating caused a considerably lower $b^{*}$ value than that of control, and the faint yellow color of WPNFs-based coating led $b^{*}$ value slightly higher than the control sample. During storage, $b^{*}$ values in all cases have exhibited remarkable rises because the cheese color was deepened due to moisture loss $(p<0.05)$. WPNFs-CA/Gly coated cheese samples have got the prime color protection (13.44\%), followed by WPNFs/Gly coating material $(22.33 \%)$. The increase of $b^{*}$ value in control sample has reached $53.54 \%$.

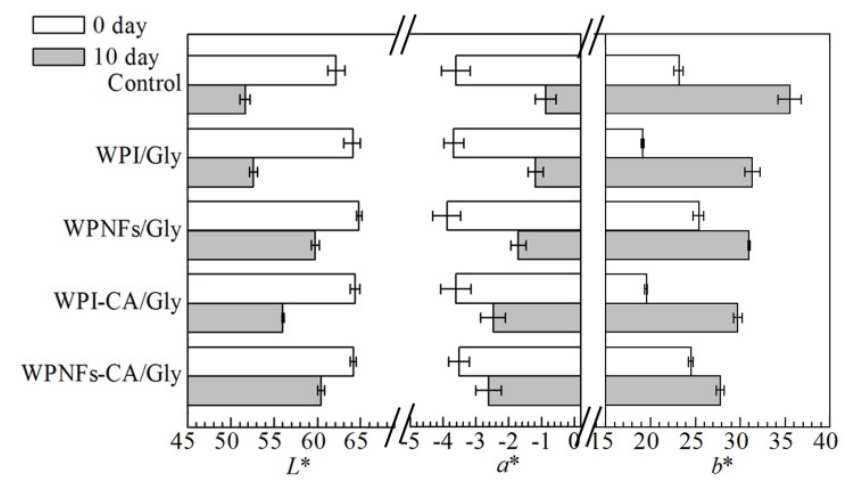

Figure 7. Color changes of coated cheeses during storage at $4{ }^{\circ} \mathrm{C}$. 


\section{Conclusions}

WPNFs could be self-assembled by $5 \%$ WPI at $80{ }^{\circ} \mathrm{C}$ incubation for $10 \mathrm{~h}$ with constantly $220 \mathrm{rpm}$ magnetic stirring. After high-pressure homogenization, the WPNFs-CA/Gly emulsion consisting of WPNFs and CA were stable enough to act as ECs of Cheddar cheese slices. Thus, the incorporation of WPNFs to the coatings may become an interesting alternative for increasing the practical value of coated cheese pieces. Compared with WPI/Gly, WPI-CA/Gly, and WPNFs/Gly emulsion and EFs, the WPNFs-CA/Gly emulsions have been proven to have higher antioxidant activity, and the WPNFs-CA/Gly films had more smooth and continuous surfaces, better transparency, lower moisture content, and higher antimicrobial activity. These characteristics make WPNFs-CA/Gly emulsion a powerful protective barrier for fresh-cut cheese. It has been proven that the Cheddar cheese coated with WPNFs-CA/Gly presented the lower weight loss and better protection capability on textural properties. These results above have proven the application prospects of WPNFs and CA as bioactive food packaging materials and WPNFs-CA/Gly emulsion as edible coating material to enhance the quality and nutritional properties of fresh-cut cheese products during storage. The WPNFs coatings may become a novel alternative to commercial coatings for fresh-cut food products.

Author Contributions: Conceptualization, Z.F. and C.L.; Data curation, Q.W., H.Y., B.J. and D.L.; Formal analysis, B.J., J.X. and D.L.; Funding acquisition, B.T. and Z.F.; Supervision, Z.F. and C.L.; Writing-Original draft, Q.W. and H.Y.; Writing-Review and editing, Z.F., and C.L.,

Funding: This research was funded by National Key Research and Development Program of China (2018YFC1604204) and Heilongjiang Nature Scientific Foundation Project (LH2019C036).

Conflicts of Interest: The authors declare no conflict of interest.

\section{References}

1. Akkermans, C.; Venema, P.; van der Goot, A.J.; Gruppen, H.; Bakx, E.J.; Boom, R.M.; van der Linden, E. Peptides are building blocks of heat-induced fibrillar protein aggregates of $\beta$-lactoglobulin formed at $\mathrm{pH} 2$. Biomacromolecules 2008, 9, 1474-1479. [CrossRef]

2. Liu, C.; Liu, W.; Feng, Z.; Li, D. Aggregation of Whey Protein Hydrolysate Using Alcalase 2.4 L. PLoS ONE 2014, 9, e109439. [CrossRef]

3. Veerman, C.; de Schiffart, G.; Sagis, L.M.C.; van der Linden, E. Irreversible self-assembly of ovalbumin into fibrils and the resulting network rheology. Int. J. Biol. Macromol. 2003, 33, 121-127. [CrossRef]

4. Akkermans, C.; Van der Goot, A.J.; Venema, P.; Gruppen, H.; Vereijken, J.M.; Van der Linden, E.; Boom, R.M. Micrometer-Sized Fibrillar Protein Aggregates from Soy Glycinin and Soy Protein Isolate. Agric. Food Chem. 2007, 55, 9877-9882. [CrossRef]

5. Munialo, C.D.; Martin, A.H.; van der Linden, E.; de Jongh, H.H. Fibril formation from pea protein and subsequent gel formation. J. Agric. Food Chem. 2014, 62, 2418-2427. [CrossRef]

6. Jiang, B.; Na, J.; Wang, L.; Li, D.; Liu, C.; Feng, Z. Separation and Enrichment of Antioxidant Peptides from Whey Protein Isolate Hydrolysate by Aqueous Two-Phase Extraction and Aqueous Two-Phase Flotation. Foods 2019, 8, 34. [CrossRef]

7. Ng, S.K.; Nyam, K.L.; Nehdi, I.A.; Chong, G.H.; Lai, O.M.; Tan, C.P. Impact of stirring speed on beta-lactoglobulin fibril formation. Food Sci. Biotechnol. 2016, 25 (Suppl. 1), 15-21. [CrossRef]

8. Mantovani, R.A.; de Figueiredo Furtado, G.; Netto, F.M.; Cunha, R.L. Assessing the potential of whey protein fibril as emulsifier. J. Food Eng. 2018, 223, 99-108. [CrossRef]

9. Moayedzadeh, S.; Madadlou, A.; Asl, A.K. Formation mechanisms, handling and digestibility of food protein nanofibrils. Trends Food Sci. Technol. 2015, 45, 50-59. [CrossRef]

10. Kroes-Nijboer, A.; Venema, P.; van der Linden, E. Fibrillar structures in food. Food Funct. 2012, 3, $221-227$. [CrossRef]

11. Jones, O.G.; Mezzenga, R. Inhibiting, promoting, and preserving stability of functional protein fibrils. Soft Matter 2012, 8, 876-895. [CrossRef]

12. Amagliani, L.; Schmitt, C. Globular plant protein aggregates for stabilization of food foams and emulsions. Trends Food Sci. Technol. 2017, 67, 248-259. [CrossRef] 
13. Chaparro-Hernández, S.; Ruíz-Cruz, S.; Márquez-Ríos, E.; Ocaño-Higuera, V.M.; Valenzuela-López, C.C.; Ornelas-Paz, J.d.J.; Del-Toro-Sánchez, C.L. Effect of chitosan-carvacrol edible coatings on the quality and shelf life of tilapia (Oreochromis niloticus) fillets stored in ice. Food Sci. Technol. 2015, 35, 734-741. [CrossRef]

14. McClements, D.J.; Decker, E.A.; Park, Y.; Weiss, J. Structural design principles for delivery of bioactive components in nutraceuticals and functional foods. Crit. Rev. Food Sci. Nutr. 2009, 49, 577-606. [CrossRef]

15. Umaraw, P.; Verma, A.K. Comprehensive review on application of edible film on meat and meat products: An eco-friendly approach. Crit. Rev. Food Sci. Nutr. 2017, 57, 1270-1279. [CrossRef]

16. Aziz, M.; Karboune, S. Natural Antimicrobial/Antioxidant Agents in Meat and Poultry Products as Well as Fruits and Vegetables: A Review. Crit. Rev. Food Sci. Nutr. 2016, 58, 1-26. [CrossRef]

17. Feng, Z.; Li, L.; Wang, Q.; Wu, G.; Liu, C.; Jiang, B.; Xu, J. Effect of Antioxidant and Antimicrobial Coating based on Whey Protein Nanofibrils with TiO(2) Nanotubes on the Quality and Shelf Life of Chilled Meat. Int. J. Mol. Sci. 2019, 20, 1184. [CrossRef]

18. Song, Y.; Liu, L.; Shen, H.; You, J.; Luo, Y. Effect of sodium alginate-based edible coating containing different anti-oxidants on quality and shelf life of refrigerated bream (Megalobrama amblycephala). Food Control 2011, 22, 608-615. [CrossRef]

19. Ojagh, S.M.; Rezaei, M.; Razavi, S.H.; Hosseini, S.M.H. Effect of chitosan coatings enriched with cinnamon oil on the quality of refrigerated rainbow trout. Food Chem. 2010, 120, 193-198. [CrossRef]

20. Wang, Q.; Lei, J.; Ma, J.; Yuan, G.; Sun, H. Effect of chitosan-carvacrol coating on the quality of Pacific white shrimp during iced storage as affected by caprylic acid. Int. J. Biol. Macromol. 2018, 106, 123-129. [CrossRef]

21. Santos, A.R.; da Silva, A.F.; Amaral, V.C.; Ribeiro, A.B.; de Abreu Filho, B.A.; Mikcha, J.M. Application of edible coating with starch and carvacrol in minimally processed pumpkin. J. Food Sci. Technol. 2016, 53, 1975-1983. [CrossRef]

22. Zhong, Y.; Cavender, G.; Zhao, Y. Investigation of different coating application methods on the performance of edible coatings on Mozzarella cheese. LWT Food Sci. Technol. 2014, 56, 1-8. [CrossRef]

23. Bolder, S.G.; Vasbinder, A.J.; Sagis, L.M.C.; van der Linden, E. Heat-induced whey protein isolate fibrils: Conversion, hydrolysis, and disulphide bond formation. Int. Dairy J. 2007, 17, 846-853. [CrossRef]

24. Feng, Z.; Li, L.; Zhang, Y.; Li, X.; Liu, C.; Jiang, B.; Xu, J.; Sun, Z. Formation of Whey Protein Isolate Nanofibrils by Endoproteinase GluC and Their Emulsifying Properties. Food Hydrocoll. 2019, 94, 71-79. [CrossRef]

25. Miliauskas, G.; Venskutonis, P.; Van Beek, T. Screening of radical scavenging activity of some medicinal and aromatic plant extracts. Food Chem. 2004, 85, 231-237. [CrossRef]

26. Schmitt, C.; Bovay, C.; Vuilliomenet, A.-M.; Rouvet, M.; Bovetto, L.; Barbar, R.; Sanchez, C. Multiscale characterization of individualized $\beta$-lactoglobulin microgels formed upon heat treatment under narrow $\mathrm{pH}$ range conditions. Langmuir 2009, 25, 7899-7909. [CrossRef]

27. Homez-Jara, A.; Daza, L.D.; Aguirre, D.M.; Munoz, J.A.; Solanilla, J.F.; Vaquiro, H.A. Characterization of chitosan edible films obtained with various polymer concentrations and drying temperatures. Int. J. Biol. Macromol. 2018, 113, 1233-1240. [CrossRef]

28. Ghani, S.; Barzegar, H.; Noshad, M.; Hojjati, M. The preparation, characterization and in vitro application evaluation of soluble soybean polysaccharide films incorporated with cinnamon essential oil nanoemulsions. Int. J. Biol. Macromol. 2018, 112, 197-202. [CrossRef]

29. Liu., Q.R.; Wang., W.; Qi., J.; Huang., Q.; Xiao, J. Oregano essential oil loaded soybean polysaccharide films: Effect of Pickering type immobilization on physical and antimicrobial properties. Food Hydrocoll. 2019, 87, 165-172. [CrossRef]

30. Arnaudov, L.N.; De, V.R.; Ippel, H.; van Mierlo, C.P. Multiple steps during the formation of beta-lactoglobulin fibrils. Biomacromolecules 2003, 4, 1614. [CrossRef]

31. Uzun, S.; Kim, H.; Leal, C.; Padua, G.W. Ethanol-induced whey protein gels as carriers for lutein droplets. Food Hydrocoll. 2016, 61, 426-432. [CrossRef]

32. Serfert, Y.; Lamprecht, C.; Tan, C.P.; Keppler, J.K.; Appel, E.; Rossier-Miranda, F.J.; Schroen, K.; Boom, R.M.; Gorb, S.; Selhuber-Unkel, C.; et al. Characterisation and use of $\beta$-lactoglobulin fibrils for microencapsulation of lipophilic ingredients and oxidative stability thereof. J. Food Eng. 2014, 143, 53-61. [CrossRef]

33. Jiang, B.; Na, J.; Wang, L.; Li, D.; Liu, C.; Feng, Z. Eco-Innovation in Reusing Food By-Products: Separation of Ovalbumin from Salted Egg White Using Aqueous Two-Phase System of PEG 1000/( $\left.\mathrm{NH}_{4}\right)_{2} \mathrm{SO}_{4}$. Polymers 2019, 11, 238. [CrossRef] 
34. Kong, J.; Yu, S. Fourier Transform Infrared Spectroscopic Analysis of Protein Secondary Structures. Acta Biochim. Biophys. Sin. 2007, 39, 549-559. [CrossRef]

35. Li, M.; Ma, Y.; Ngadi, M.O. Binding of curcumin to beta-lactoglobulin and its effect on antioxidant characteristics of curcumin. Food Chem. 2013, 141, 1504-1511. [CrossRef]

36. Xue, J.; Zhang, Y.; Huang, G.; Liu, J.; Slavin, M.; Yu, L. Zein-caseinate composite nanoparticles for bioactive delivery using curcumin as a probe compound. Food Hydrocoll. 2018, 83, 25-35. [CrossRef]

37. Mohammadian, M.; Salami, M.; Momen, S.; Alavi, F.; Emam-Djomeh, Z.; Moosavi-Movahedi, A.A. Enhancing the aqueous solubility of curcumin at acidic condition through the complexation with whey protein nanofibrils. Food Hydrocoll. 2019, 87, 902-914. [CrossRef]

38. Mohammadian, M.; Madadlou, A. Cold-set hydrogels made of whey protein nanofibrils with different divalent cations. Int. J. Biol. Macromol. 2016, 89, 499-506. [CrossRef]

39. Artiga-Artigas, M.; Acevedo-Fani, A.; Martín-Belloso, O. Improving the shelf life of low-fat cut cheese using nanoemulsion-based edible coatings containing oregano essential oil and mandarin fiber. Food Control 2017, 76, 1-12. [CrossRef]

40. Weiss, J.; Takhistov, P.; McClements, D.J. Functional Materials in Food Nanotechnology. J. Food Sci. 2006, 71, R107-R116. [CrossRef]

41. Teixeira, B.; Marques, A.; Pires, C.; Ramos, C.; Batista, I.; Saraiva, J.A.; Nunes, M.L. Characterization of fish protein films incorporated with essential oils of clove, garlic and origanum: Physical, antioxidant and antibacterial properties. LWT Food Sci. Technol. 2014, 59, 533-539. [CrossRef]

42. Priyadarshi, R.; Sauraj; Kumar, B.; Deeba, F.; Kulshreshtha, A.; Negi, Y.S. Chitosan films incorporated with Apricot (Prunus armeniaca) kernel essential oil as active food packaging material. Food Hydrocoll. 2018, 85, 158-166. [CrossRef]

43. Feng, Z.; Wu, G.; Liu, C.; Li, D.; Jiang, B.; Zhang, X. Edible coating based on whey protein isolate nanofibrils for antioxidation and inhibition of product browning. Food Hydrocoll. 2018, 79, 179-188. [CrossRef]

44. Bermudez-Aguirre, D.; Barbosa-Canovas, G.V. Processing of soft Hispanic cheese ("queso fresco") using thermo-sonicated milk: A study of physicochemical characteristics and storage life. J. Food Sci. 2010, 75, S548-S558. [CrossRef] [PubMed] 